\title{
Grey Correlative Degree Analysis on the Cold-Resistant Traits of Parthenocarpic Eggplant
}

\author{
Ling Ling $\mathrm{Lv}^{1,2,3}$, Wei $\mathrm{Li}^{1,2,3}$, Xi Ou Xiao ${ }^{1,2,3}$ \& Xiao Min Gao ${ }^{1,2,3}$ \\ ${ }^{1}$ South Subtropical Crops Research Institute, CATAS, Zhanjiang, Guangdong, China \\ ${ }^{2}$ Construction on the Research and Development Center of Industry Technology for Provincial Modern \\ Agriculture (Key Tropical Crops), Zhanjiang, Guangdong, China \\ ${ }^{3}$ Zhanjiang City Key Laboratory for Tropical Crops Genetic Improvement, Zhanjiang, Guangdong, China \\ Correspondence: Ling Ling Lv, South Subtropical Crops Research Institute, CATAS, Zhanjiang, Guangdong \\ 524091, China. Tel: 86-759-285-9139. E-mail: 15133253@qq.com
}

Received: March 4, 2017

doi:10.5539/jas.v9n10p95

\author{
Accepted: July 31, 2017 Online Published: September 15, 2017 \\ URL: https://doi.org/10.5539/jas.v9n10p95
}

\begin{abstract}
In order to breed new eggplant variety with parthenocarpic ability and strong cold-resistance, the six cold-resistant traits of fifteen eggplant resources with parthenocarpic ability were evaluated with grey correlative degree analysis. One non-parthenocarpic resource 'Shenggao No. 2' was used as control. The results indicated that '29', '32', '30', 'XBL', '31-2-1', 'TXQ' and '31-2-2' had strong cold-resistance; 'HLMQ', 'HQ', 'ZHQ', control and 'HXZ' had weak cold-resistance; the other four resources had moderate cold-resistance. When suffered cold stress, the resources with strong cold-resistance had a larger increase of SOD, POD, CAT activities and a least increase of MDA content and EL. Among the strong cold-resistant resources, '29', '30', '31-2-1', 'TXQ' and '31-2-2' had purplish red fruits and significantly stronger cold-resistance than control, which were suitable for cultivation in south China. '32' and 'XBL' with white fruits could be used as breeding materials.
\end{abstract}

Keywords: eggplant, cold-resistance, parthenocarpy, grey correlative degree analysis, antioxidase

\section{Introduction}

As an agronomically important solanaceous crop, eggplant (Solanum melongena L.) is a kind of thermophile vegetable and is widely grown in both north and south China. It often encounters chilling injury in winter and early spring cultivation, which results in delaying the growth, declining of yield and quality. The optimum growth temperature for eggplant is $22-30{ }^{\circ} \mathrm{C}$. When temperature is lower than $17{ }^{\circ} \mathrm{C}$, the eggplant growth will be slowed down; when lower than $10{ }^{\circ} \mathrm{C}$, the plant will suffer metabolic disturbance (Song, 2011).

Under cold stress, eggplant resources with parthenocarpic ability can bear large number of fruits without pollination while the non-parthenocarpic resources can't fruit. Parthenocarpy can overcome loosing flowers and fruits, improve yield and reduce cost. Meanwhile, parthenocarpic fruits have no seed, which improves quality (Gao et al., 2012). To mitigate these defects in fruit set under low temperature, the breeding of parthenocarpic variety may be a cost-effective alternative.

Parthenocarpic round eggplant with strong cold-resistance was screened out from local varieties (Liu et al., 2005). Pan et al. (2005) found parthenocarpic material from inbred lines of round eggplant. Some parthenocarpic lines suitable for protected cultivation were selected from abroad eggplants (Zhang et al., 2008; Yang et al., 2009). However, the parthenocarpic lines selected already are suitable for cultivation in north China, the purplish red and long eggplant with parthenocarpic ability and suitable for cultivation in south China has not been selected yet.

The antioxidant enzymes such as peroxidase (POD), superoxide dismutase (SOD) and catalase (CAT) have been extensively studied for their roles in plant defense (Aniszewski et al., 2008; Kong et al., 2015; Shi et al., 2015; Wei et al., 2016). Malondialdehyde (MDA) content, electrolyte leakage (EL) and chilling injury (CI) index are closely related to cold-resistance (Shi et al., 2015; Wei et al., 2016). Grey correlative degree analysis is one of the multi-parameter diagnostic methods, which was conducted to make a comprehensively quantitative evaluation on sixteen eggplant resources according to their six main cold-resistant traits. It would help to know 
the relationship between parthenocarpy and cold-resistance, which would also lay foundation for breeding new variety with strong cold-resistance and suitable for cultivation in south China.

\section{Materials and Methods}

\subsection{Plant Materials}

Sixteen eggplant resources were used as materials, the characters of which were showed in Table 1. 'Shenggao No. 2' without parthenocarpic ability was used as control. The seedlings with four leaves of sixteen eggplant resources were cultivated in incubators.

Table 1. The characters of sixteen eggplant resources

\begin{tabular}{|c|c|c|c|c|c|c|c|}
\hline Eggplant resource & $\begin{array}{l}\text { With or without } \\
\text { parthenocarpic } \\
\text { ability }\end{array}$ & Fruit shape & Fruit color & Eggplant resource & $\begin{array}{l}\text { With or without } \\
\text { parthenocarpic } \\
\text { ability }\end{array}$ & Fruit shape & Fruit color \\
\hline $\mathrm{HXZ}$ & Yes & Long cylindric & Light purple & $31-2-2$ & Yes & Long cylindric & Purplish red \\
\hline $\mathrm{HL}$ & Yes & Short cylindric & Blackish purple & 32 & Yes & Long cylindric & White \\
\hline HQ & Yes & Long stick & Purplish red & ZHQ & Yes & Long cylindric & Purplish red \\
\hline XBL & Yes & Long cylindric & White & 49 & Yes & Long cylindric & Green \\
\hline Control & No & Long cylindric & Purplish red & TXQ & Yes & Long cylindric & Purplish red \\
\hline 29 & Yes & Long cylindric & Purplish red & HLMQ & Yes & Long cylindric & Blackish purple \\
\hline 30 & Yes & Long cylindric & Purplish red & GQ & Yes & Long cylindric & Blackish purple \\
\hline $31-2-1$ & Yes & Long cylindric & Purplish red & $59-1$ & Yes & Long cylindric & Blackish purple \\
\hline
\end{tabular}

\subsection{Experimental Treatment and Sample Preparation}

Firstly, the seedlings were precultured at $20{ }^{\circ} \mathrm{C} / 10{ }^{\circ} \mathrm{C}$ (light $12 \mathrm{~h} /$ dark $12 \mathrm{~h}$ ) for 2 days ; then treated at $5{ }^{\circ} \mathrm{C} / 5{ }^{\circ} \mathrm{C}$ (light $12 \mathrm{~h} /$ dark $12 \mathrm{~h}$ ) for 4 days; finally, recovered at $30{ }^{\circ} \mathrm{C} / 20{ }^{\circ} \mathrm{C}$ for 2 days. At the four stages: after preculture $(2 \mathrm{~d})$, treated at $5{ }^{\circ} \mathrm{C}$ for 2 days $(4 \mathrm{~d})$ and 4 days $(6 \mathrm{~d})$, recovered for 2 days $(8 \mathrm{~d})$, the leaves were taken for analyzing the activities of antioxidase and MDA content. The weight of each sample was $0.5 \mathrm{~g}$. After weighing, leaves were immediately frozen in liquid nitrogen, then stored at $-80{ }^{\circ} \mathrm{C}$ until use. At the above four stages, fresh leaves were taken respectively and immediately used for EL analysis. The experiment was repeated three times (three independent samples).

\subsection{Index}

On the sixth and eighth day, external CI symptoms were visually analyzed. CI was determined according to the following scale: $0=$ no damage, $1=$ the edge of the leaf wilting, $2=$ one leaf wilting, $3=$ two leaves wilting, $4=$ over two leaves wilting. Observations were made on 20 plants for each resource. The CI index was calculated according to the following equation:

\subsection{The Activity of SOD, POD and CAT}

$$
\text { CI Index }=\frac{\sum(\text { Injury level } \times \text { Number of plants at that level })}{\text { The highest level } \times \text { total number of plants }}
$$

For sample preparation, $0.5 \mathrm{~g}$ leaves were ground in a mortar with $5 \mathrm{ml} 0.2 \mathrm{~mol} / \mathrm{L}$ phosphate buffer solution $(\mathrm{pH}$ $=7.0$ ). The suspension was transferred to a tube, then mixed and centrifuged at $12,000 \mathrm{rpm}$ for $15 \mathrm{~min}$ at $4{ }^{\circ} \mathrm{C}$. The supernatant was collected. Three extracts were done for each resource.

The SOD activity was measured using Total Superoxide Dismutase assay kit (Hydroxylamine method) (Nanjing jiancheng bioengineering institute) following the manufacturer's instructions. SOD activity was calculated as the Equation (2):

$$
\text { SOD activity }\left(\mathrm{u} \cdot \mathrm{g}^{-1} \text { fresh weight }\right)=\frac{2 \times(\mathrm{Ack}-\mathrm{Ae}) \times \mathrm{Vt} \times \mathrm{V} 2}{\mathrm{Ack} \times \mathrm{V} 1 \times \mathrm{W}}
$$

Where,

Ack: the absorbance of control; Ae: the absorbance of sample; Vt: the volume of the reaction liquid (ml); W: the fresh weight (FW) of leaves (g); V1: the volume of the enzyme solution in reaction liquid (ml); V2: the total volume of the enzyme extraction $(\mathrm{ml})$. 
The POD activity was measured by guaiacol method (Wu et al., 2006), which was calculated as the following equation:

$$
\text { POD activity }\left(\Delta \mathrm{A}_{470} \cdot \mathrm{g}^{-1} \mathrm{FW} \cdot \mathrm{min}^{-1}\right)=\frac{\Delta \mathrm{A}_{470} \times \mathrm{V} 2}{\mathrm{~W} \times \mathrm{V} 1 \times \mathrm{t}}
$$

Where,

$\Delta \mathrm{A}_{470}$ : the variation of the absorbance during the reaction time; $\mathrm{V} 2$ : the total volume of the enzyme extraction $(\mathrm{ml})$; W: the $\mathrm{FW}$ of leaves (g); V1: the volume of the enzyme solution in reaction liquid $(\mathrm{ml})$; $\mathrm{t}$ : the reaction time (min).

The CAT activity was measured by ultraviolet absorption method ( $\mathrm{Li}, 2005)$, which was calculated as the Equation (4):

$$
\text { CAT activity }\left(\mathrm{u} \cdot \mathrm{g}^{-1} \mathrm{FW} \cdot \mathrm{min}^{-1}\right)=\frac{\Delta \mathrm{A}_{240} \times \mathrm{V} 2}{0.1 \times \mathrm{W} \times \mathrm{V} 1 \times \mathrm{t}}
$$

Where,

$\Delta \mathrm{A}_{240}$ : the variation of the absorbance during the reaction time; $\mathrm{V} 2$ : the total volume of the enzyme extraction $(\mathrm{ml})$; W: the FW of leaves (g); V1: the volume of the enzyme solution in reaction liquid (ml); t: the reaction time (min).

\subsection{MDA Content}

MDA content was measured using thiobarbituric acid (TBA) method (Ma, 2009). $0.5 \mathrm{~g}$ leaves were ground in a mortar with $5 \mathrm{ml} \mathrm{5 \%}$ trichloroacetic acid (TCA). The suspension was transferred to a tube and centrifuged at 3,000 rpm for $10 \mathrm{~min}$ at room temperature. $3 \mathrm{ml}$ supernatant and $3 \mathrm{ml} \mathrm{TBA}$ were mixed and boiling for $30 \mathrm{~min}$. The absorbance of supernatant at $450 \mathrm{~nm}, 532 \mathrm{~nm}$ and $600 \mathrm{~nm}$ was measured. Blank control: $3 \mathrm{ml}$ TCA $+3 \mathrm{ml}$ TBA. Three extracts were done for each resource. MDA content was calculated as Equation (5):

$$
\text { MDA content }\left(\mu \mathrm{mol} \cdot \mathrm{g}^{-1} \mathrm{FW}\right)=\frac{\left[6.45 \times\left(\mathrm{A}_{532}-\mathrm{A}_{600}\right)-0.56 \times \mathrm{A}_{450}\right] \times \mathrm{Vt} \times \mathrm{V} 2}{1000 \times \mathrm{V} 1 \times \mathrm{W}}
$$

Where,

Vt: the volume of the reaction liquid (ml); V2: the total volume of the enzyme extraction (ml); W: the FW of leaves (g); V1: the volume of the enzyme solution in reaction liquid $(\mathrm{ml})$.

\subsection{Electrolyte Leakage}

EL was analyzed as described in the experimental guide (Chen \& Wang, 2006). Ten discs $(1 \mathrm{~cm} \times 1 \mathrm{~cm})$ from the leaves were obtained with a hole-punch and rinsed with deionized water for three times. When dried out with filter paper, the leaves were soaked in $10 \mathrm{ml}$ deionized water for $2.5 \mathrm{~h}$. The conductivity of the bathing solution was measured with a conductimeter (R1). Afterwards, the bathing solution was boiled for $15 \mathrm{~min}$, when cooled to room temperature, the conductivity of the bathing solution was measured (R2). EL was calculated as: $\mathrm{EL}=$ $\mathrm{R} 1 / \mathrm{R} 2 \times 100 \%$. Measurements were done in triplicate.

\subsection{Data Analysis}

Microsoft Excel 2010 and DPS v7.05 were used for data collecting and analyzing.

Grey correlative degree analysis: Sixteen eggplant resources could be considered as a grey system, in which each resource was a contributing factor. Now suppose there were $\mathrm{i}$ eggplant resources and $\mathrm{j}$ main cold-resistant traits which would be analyzed. 'Reference resource' had the best cold-resistant traits, which consisted of the reference data array $\mathrm{X}_{0}$, and each cold-resistant trait of test resources consisted of $\mathrm{Xi}$ accordingly. $\mathrm{Kj}$ represented each cold-resistant trait. The averages of cold-resistant traits on the sixth day were showed in Table 2. 
Table 2. Main cold-resistant traits of reference resource and test resources

\begin{tabular}{llllllll}
\hline \multirow{2}{*}{ Serial number } & Eggplant resource & $\mathrm{K}_{1}$ & $\mathrm{~K}_{2}$ & $\mathrm{~K}_{3}$ & $\mathrm{~K}_{4}$ & $\mathrm{~K}_{5}$ & $\mathrm{~K}_{6}$ \\
\cline { 3 - 8 } & SOD activity & POD activity & CAT activity & MDA content & EL & CI index \\
\hline $\mathrm{X}_{0}$ & Reference resource & 1078.000 & 20.800 & 76.000 & 0.000 & 0.150 & 0.110 \\
$\mathrm{X}_{1}$ & $\mathrm{HXZ}$ & 872.600 & 12.100 & 43.650 & 0.018 & 0.263 & 0.730 \\
$\mathrm{X}_{2}$ & $\mathrm{HL}$ & 896.600 & 19.000 & 28.280 & 0.018 & 0.204 & 0.460 \\
$\mathrm{X}_{3}$ & $\mathrm{HQ}$ & 875.600 & 20.400 & 31.540 & 0.019 & 0.351 & 1.000 \\
$\mathrm{X}_{4}$ & $\mathrm{XBL}$ & 951.700 & 19.570 & 41.120 & 0.018 & 0.156 & 0.500 \\
$\mathrm{X}_{5}$ & Control & 953.700 & 16.130 & 39.880 & 0.025 & 0.328 & 0.910 \\
$\mathrm{X}_{6}$ & 29 & 1075.500 & 20.770 & 64.140 & 0.014 & 0.225 & 0.217 \\
$\mathrm{X}_{7}$ & 30 & 885.000 & 14.050 & 75.880 & 0.012 & 0.371 & 0.140 \\
$\mathrm{X}_{8}$ & $31-2-1$ & 963.700 & 13.040 & 71.360 & 0.012 & 0.285 & 0.516 \\
$\mathrm{X}_{9}$ & $31-2-2$ & 961.400 & 17.840 & 64.140 & 0.009 & 0.282 & 0.786 \\
$\mathrm{X}_{10}$ & 32 & 1018.900 & 15.270 & 72.270 & 0.015 & 0.237 & 0.117 \\
$\mathrm{X}_{11}$ & ZHQ & 817.000 & 16.900 & 52.390 & 0.008 & 0.311 & 0.956 \\
$\mathrm{X}_{12}$ & 49 & 908.100 & 15.220 & 54.200 & 0.016 & 0.206 & 0.930 \\
$\mathrm{X}_{13}$ & TXQ & 943.900 & 11.980 & 62.270 & 0.013 & 0.269 & 0.317 \\
$\mathrm{X}_{14}$ & HLMQ & 1026.500 & 14.150 & 27.100 & 0.014 & 0.206 & 0.950 \\
$\mathrm{X}_{15}$ & GQ & 930.800 & 17.610 & 42.260 & 0.015 & 0.228 & 0.875 \\
$\mathrm{X}_{16}$ & 59-1 & 992.000 & 16.020 & 22.580 & 0.010 & 0.177 & 0.875 \\
\hline
\end{tabular}

MDA content, EL and CI index were negative traits, and the data would be converted according to '1-actual data'. For contrast, all the data of cold-resistant traits would be initialized. Equal-weighted correlative degree would be calculated according to the equation below:

$$
\begin{gathered}
\varepsilon_{i}(k)=\frac{\operatorname{minmin}_{i \ldots k}\left|x_{0}(k)-x_{i}(k)\right|+\rho \operatorname{maxmax}_{i \ldots k}\left|x_{0}(k)-x_{i}(k)\right|}{\left|x_{0}(k)-x_{i}(k)\right|+\rho \operatorname{maxmax}_{i \ldots k}\left|x_{0}(k)-x_{i}(k)\right|} \\
r_{i}=\frac{1}{n} \sum_{k=1}^{n} \varepsilon_{i}(k)
\end{gathered}
$$

In the formula, the letter ' $\mathrm{n}$ ' stands for the number of cold-resistant traits, ' $\varepsilon_{i}(k)$ ' stands for the correlative coefficient of $\mathrm{X}_{\mathrm{i}}$ to $\mathrm{X}_{0}$, ' $\rho$ ' represents identification coefficient (artificial setting 0.5), and ' $r$ ' represents the equal-weighted correlative degree of test resources (Table 2).

\section{Results}

\subsection{Chilling Injury Index}

On the sixth day, the CI indexes of '30', '32', '29', 'TXQ', 'HL', 'XBL', '31-2-1', 'HXZ' and '31-2-2' were significantly lower than that of control, which indicated they had stronger cold-resistance than control (Figure 1). However, the CI indexes of 'HQ', 'ZHQ' and 'HLMQ' were significantly higher than that of control, and visible symptoms of CI were detected in 'HQ'. When recovered for 2 days, only the CI index of ' $\mathrm{HL}$ ' kept increasing to 0.74 , which suggested the recovery capability of ' $\mathrm{HL}$ ' was relatively weak; the $\mathrm{CI}$ index of other resources decreased rapidly. 


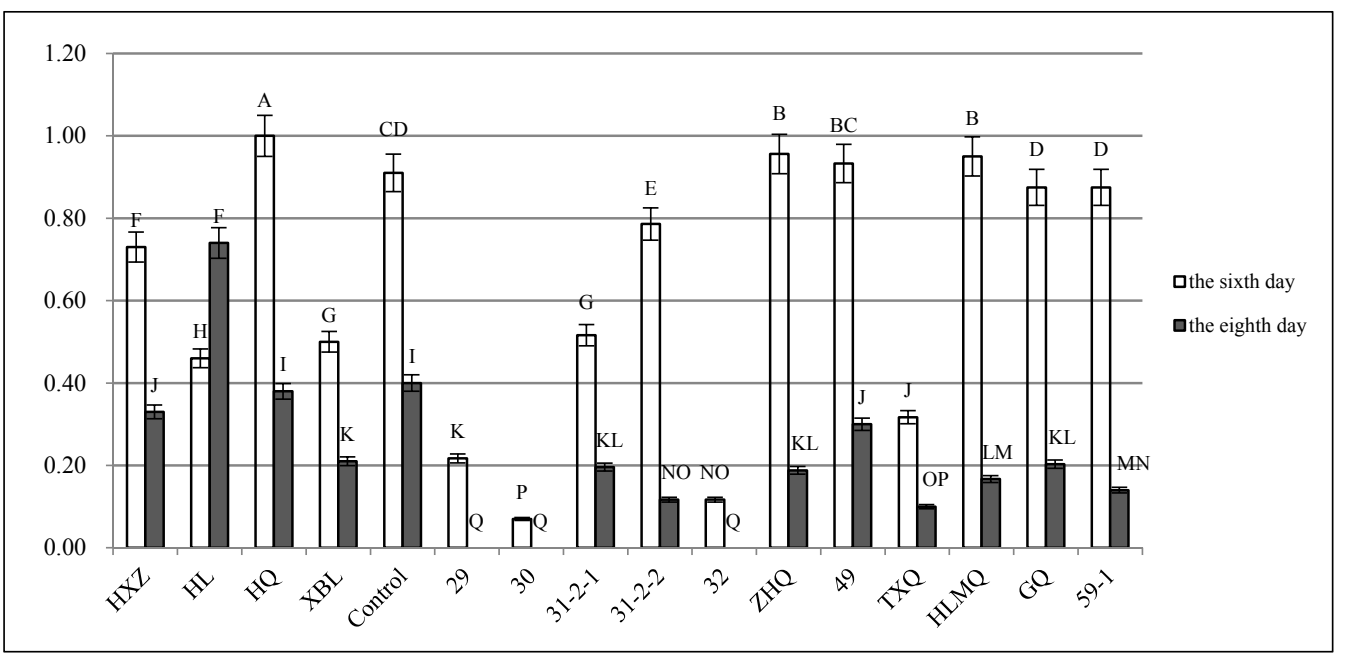

Figure 1. Chilling injury index of sixteen resources on the sixth and eighth day

Note. The capital letters show significantly different $(P<0.01)$. Percent error line $(5 \%)$.

\subsection{The SOD, POD and CAT Activities}

Under cold stress, SOD, POD and CAT activities of all resources increased (Appendix A-C). However, the SOD, POD and CAT activities of some resources reached the peak on the fourth day, some on the sixth day. The resources with stronger cold-resistance had a larger increase of SOD, POD and CAT activities than those with weaker cold-resistance.

\subsection{MDA Content and EL}

At the first three stages, the MDA content and EL of all resources increased (Appendix D-E), when recovered for 2 days, all MDA content and EL decreased. The resources with stronger cold-resistance had a least increase of MDA content and EL, which suggested they had the least damage.

\subsection{Grey Correlative Degree Analysis}

According to the equal-weighted correlative degree, the test resources were ranked (Table 3). The results showed ' 29 ' had the largest correlative degree $(r=0.899)$ with the reference resource, which revealed ' 29 ' had the strongest cold-resistance, followed by ' 32 ' and ' 30 ', with the value of 0.877 and 0.820 respectively. 'HXZ' had the smallest correlative degree of 0.665 , which was smaller than that of control.

Table 3. The equal-weighted correlative degree of test resources

\begin{tabular}{llll|llll}
\hline Serial number & Eggplant resource & $\begin{array}{l}\text { Equal-weighted } \\
\text { correlative degree }\end{array}$ & Rank & Serial number & Eggplant resource & $\begin{array}{l}\text { Equal-weighted } \\
\text { correlative degree }\end{array}$ & Rank \\
\hline X6 & 29 & 0.899 & 1 & X15 & GQ & 0.712 & 9 \\
X10 & 32 & 0.877 & 2 & X12 & 49 & 0.710 & 10 \\
X7 & 30 & 0.820 & 3 & X16 & $59-1$ & 0.710 & 10 \\
X4 & XBL & 0.787 & 4 & X14 & HLMQ & 0.695 & 12 \\
X8 & $31-2-1$ & 0.759 & 5 & X3 & HQ & 0.689 & 13 \\
X13 & TXQ & 0.754 & 6 & X11 & ZHQ & 0.680 & 14 \\
X9 & $31-2-2$ & 0.752 & 7 & X5 & Control & 0.673 & 15 \\
X2 & HL & 0.744 & 8 & X1 & HXZ & 0.665 & 16 \\
\hline
\end{tabular}

\subsection{Cold-Resistance Grade Classification}

According to the correlative degree (Table 3), test resources could be divided into three grades. When the correlative degree was over 0.750 , the test resources had strong cold-resistance, so '29', '32', '30', 'XBL', '31-2-1', 'TXQ' and ' $31-2-2$ ' had strong cold-resistance. When the correlative degree was more than 0.700 and 
less than 0.750 , the test resources had moderate cold-resistance, 'HL', 'GQ', '49' and ' $59-1$ ' belonged to this kind. When less than 0.700 , the test resources had weak cold-resistance.

\section{Discussion}

Visible symptom of chilling injury is wilting of leaves. CI index had significant negative correlation with cold-resistance, which was also an important index to evaluate the cold-resistance in seedling stage (Wang et al., 2015b). The result of CI index was highly consistent with that of grey correlative degree. One main difference was ' $\mathrm{HL}$ ' had strong cold-resistance according to $\mathrm{CI}$ index and moderate cold-resistance according to the latter. So combined with other cold-resistant traits, CI index could evaluate more objectively.

In order to clear away the harmful materials caused by cold stress, the activity of antioxidase such as SOD, POD and CAT will increase rapidly (Fu et al., 2010; Hao et al., 2014; Yan et al., 2011). The variety with strong cold-resistance had a larger increase of SOD and POD activities (Zhang \& Yan, 2013).Wang et al. (2013) reported that rice with extremely strong chilling-tolerance had a bigger jump of SOD and POD activities than chilling-sensitive rice. Under cold water stress, CAT activity of chilling-sensitive rice and chilling-tolerant rice increased significantly (Wang, 2015). Jia et al. (2011) reported that CAT activity of wild Lily species with strong cold-resistance increased and maintained a higher level when treated at $11^{\circ} \mathrm{C} / 5^{\circ} \mathrm{C}$ (day/night). The results in this work were in accordance with these reports.

Low temperature is harmful to the cell membrane system which causes the selectivity of cell membrane lost and MDA produced. Electrolyte and small molecule organic compounds will permeate out, which lead to the increase of relative conductivity. Under cold stress, materials with strong cold-resistance had a smaller change in MDA content and EL (Zhang et al., 2012, 2013; Wang et al., 2013).

Grey correlative degree analysis is one of the multi-parameter diagnostic methods, which was applied in many crops (Yang et al., 2012; Wang, 2013; Long, 2013; Xing, 2015; Lu et al., 2016; Wang et al., 2015a; Chen et al., 2016). Through grey correlative degree analysis, Chen et al. (2015) selected two varieties which were better than control in agronomic traits and disease-resistance. In this work, cold-resistance of sixteen resources was analyzed. Among the fifteen resources with parthenocarpic ability, only one resource had weaker cold-resistance than control, so most of the resources with parthenocarpic ability had strong cold-resistance.

According to the equal-weighted correlative degree, the resources were divided into three grades. Seven resources had strong cold-resistance and five resources including control had weak cold-resistance. '29', '30', '31-2-1', 'TXQ' and '31-2-2' had purplish red fruits and significantly stronger cold-resistance than control, which were suitable for cultivation in south China. '32' and 'XBL' with white fruits could be used as breeding materials.

\section{Acknowledgements}

This work was funded by the Project of Natural Science Foundation of Guangdong Province (2015A030310452) and the Fundamental Research Funds for South Subtropical Crops Research Institute, CATAS (1630062014005). The authors are thankful to colleagues Zhiwei Jia and Weihai Yang for providing necessary facilities and techniques to conduct the experiments. There are no conflicts of interest.

\section{References}

Aniszewski, T., Lieberei, R., \& Gulewicz, K. (2008). Research on catecholases, laccases and cresolases in plants. Recent progress and future needs. Acta Biol Cracov Bot., 50, 7-18.

Chen, H. L., Chen, Z., Guo, Y. Z., Huang, Q., \& Lin, H. H. (2015). Grey correlative degree analysis on introduced varieties of eggplant. Anhui Agri. Sci. Bull., 21(2), 46-48.

Chen, J. X., \& Wang, X. F. (2006). Experimental guide for plant physiology. South China University of Technology Press, Guangzhou, China.

Chen, L. Z., Xiao, R. S., Lin, D. Y., Luo, F., \& Yang, X. F. (2016). Comprehensive assessment for Abelmoschus esculentus L. cultivars based on grey correlation analysis. Journal of Southern Agri., 47(3), 419-423.

Fu, X. M., Zhu, H. L, Li, X. J., Wu, H., He, G. H., Xie, J., \& Chen, Y. H. (2010). Effects of NaCl stress on the growth and physio-biochemical characteristics of rice seedlings. Guangdong Agri. Sci., 4, 19-21.

Gao, X. R., Li, B., Gao, H. B., Wu, Y. R., \& Pan, X. Q. (2012). Effects of low temperature stress on physiological characteristics of parthenocarpic eggplant seedlings. Chinese Agri. Sci. Bull., 28(19), 123-129. 
Hao, X. Q., Yao, P. H., Gao, Z. R., \& Wu, Z. K. (2014). Effects of low temperature stress on the physiological and biochemical characteristics of cold resistance in micro-endosperm super sweet and super high oil maize. Acta Agronomica Sinica, 40(8), 1470-1484. https://doi.org/10.3724/SP.J.1006.2014.01470

Jia, W. J., Zhang, Y. P., Cui, G. F., Wu, L. F., Ma, L. L., \& Zhang, H. (2011). Study on cold-resistance of seedlings of different Lily. Southwest China Journal of Agri. Sci., 24(3), 905-910.

Kong, F., Liu, Q. E., Du, K., \& Wang, Y. P. (2015). Physiological response of newly synthesized brassica napus and its parents at seedling stage under drought stress. Journal of Yangzhou University (Agricultural and Life Science Edition), 36(2), 46-50.

Li, H. B. (2005). Effect of chitosan on inducing the heat-resistance of vegetable and its possible physiological mechanism (The dissertation for Master degree, Zhejiang University, Hangzhou, China).

Liu, F. Z., Lian, Y., Chen, Y. H., \& Song, Y. (2005). The effect of temperature and bud stage treatment on parthenocarpic gene expression of eggplant. Acta Horticulture Sinica, 32(6), 1021-1025.

Long, L. (2013). Germplasm evaluation of Pinelliaiernata (Thunb.) Breit. by gray correlation degree (The dissertation for Master degree, Huazhong Agricultural University, Wuhan, China).

Lu, X., Mao, J., Lin, X. Q., Wang, X. Y., Liu, X. L., Liu, H. B., Su, H. S., \& Cai, Q. (2016). Studies on innovation utilization of erianthus rockii germplasm IV. A integrated evaluation of breeding potential of F1 progenies of erianthus rockii using grey multidimensional degree analysis. Sugar Crops of China, 38(1), $1-4$.

Ma, L. Y. (2009). Effects of different rootstocks on cold tolerance and nutritional quality of eggplant (The dissertation for Master degree, Henan Agricultural University, Zhengzhou, China).

Pan, X. Q., Wu, Y. R., \& Gao, X. R. (2005). Discovery of parthenocarpy D-11 in eggplant. Acta Agri. Boreali-Sinica, 20(6), 33.

Shi, H. M., Zhang, H. Y., Yang, B., \& Zhang, G. X. (2015). Effects of low temperature stress on the content of MDA, SOD and POD activity in sorghum seedlings. Chinese Agri. Sci. Bull., 31(18), 74-79.

Song, Y. J. (2011). Studies on physiological characteristics and its regulation of eggplant seedlings under sub-low temperature condition (The dissertation for Master degree, Qingdao Agricultural College, Qingdao, China).

Wang, G. J., Wang, J. Y., Ma, D. R., Miao, W., Zhao, M. H., \& Chen, W. F. (2015). Responses of antioxidant system to cold water stress in weedy and cultivated rice with different chilling sensitivity. Scientia Agricultura Sinica, 48(8), 1660-1668.

Wang, G. J., Wang, J. Y., Miao, W., Zhao, M. H., \& Chen, W. F. (2013). Responses of antioxidant system to long-term cold water stress in new rice line J07-23 with strong cold resistance. Acta Agronomica Sinica, 39(4), 753-759. https://doi.org/10.3724/SP.J.1006.2013.00753

Wang, H. B. (2013). Evaluation of drought resistance and analysis of genetic diversity in cotton varieties under drought stress of seedling stage and flowering stage (The dissertation for Master degree, Xinjiang Agricultural University, Urumqi, China).

Wang, H. F., Li, X. X., Wang, H. P., Song, J. P., Qiu, Y., Zhang, X. H., \& Shen, D. (2015b). Preliminary studies on identification method for cucumber tolerance to low temperature. China Vegetables, 3, 17-25.

Wang, Z. R., Yan, Z., Yan, Z. L., Jiang, Z. H., Lu, C. X., Xiao, S. X., ... Weng, B. Q. (2015a). Grey correlation analysis on relationships between mineral elements and $\mathrm{Cd}$ contents in Pleurotus geesteranus fruit body. Chinese Journal of Tropical Crops, 36(12), 2291-2294.

Wei, X. Q., Xu, L., Zhang, X. J., Yu, D., Chen, Z. F., Zhang, L. M., \& Xu, J. H. (2016). Physiological responses of wax apple to low temperatures and its cold resistance. Journal of Fruit Sci., 33(1), 73-80.

Wu, X. X., Zhu, Y. L., Zhu, W. M., Chen, J. L., \& Liu, Z. L. (2006). Physiological effects of exogenous nitric oxide in tomato seedlings under NaCl stress. Scientia Agri Sinica, 39(3), 575-581.

Xing, Y. Y. (2015). Effect of water and fertilizer coupling on greenhouse tomato under fertigation (The dissertation for Doctor degree, Northwest A\&F University, Yangling, China).

Yan, S. J., Zhang, J. N., \& Liu, J. (2011). Physiological mechanism of chilling tolerance in eggplant seedling. Acta Bot. Boreal-Occident Sin., 31(12), 2498-2502. 
Yang, G. D., Li, H. T., Lv, S. W., \& Zhang, H. Y. (2009). Breeding of parthenocarpic eggplant hybrid 'Liaoqie 16'. Northern Horticulture, 7, 173-174.

Yang, W. H., Zhang, M. K., Zou, M. H., Zeng, H., Zhang, H. Z., \& Lu, C. Z. (2012). Grey correlative degree analysis and fuzzy comprehensive evaluation on the main quality characters of macadamia. Chinese Journal of Tropical Crops, 33(10), 1743-1748.

Zhang, J. N., \& Yan, S. J. (2013). Effects of chilling stress on biochemical indexes of eggplant seedlings. Journal of Hebei Normal University of Science \& Technology, 27(3), 10-13.

Zhang, J., \& Zhu, W. M. (2012). Effects of chilling stress on contents of chlorophyll and malondialdehyde in tomato seedlings. Acta Agriculturae Shanghai, 28(3), 74-77.

Zhang, W. C., Wei, Y. T., Wang, J., He, M., \& Tang, P. (2008). Observation of embryo development and fruit anatomic structure of parthenogenetic and non-parthenogenetic eggplants. Journal of Shenyang Agri. University, 39(5), 534-537.

\section{Appendix}

Appendix A. The mean values of CAT activity

\begin{tabular}{lllll}
\hline CAT activity & $2 \mathrm{~d}$ & $4 \mathrm{~d}$ & $6 \mathrm{~d}$ & $8 \mathrm{~d}$ \\
\hline HXZ & 28.80 & 34.40 & 43.65 & 17.70 \\
HL & 24.88 & 42.60 & 28.28 & 29.28 \\
HQ & 30.68 & 33.80 & 31.54 & 34.46 \\
XBL & 18.36 & 26.52 & 41.12 & 25.48 \\
Control & 25.24 & 34.8 & 39.88 & 29.82 \\
29 & 25.29 & 72.27 & 64.14 & 19.88 \\
30 & 26.65 & 57.81 & 75.88 & 18.07 \\
$31-2-1$ & 29.81 & 69.56 & 71.36 & 44.26 \\
$31-2-2$ & 36.13 & 69.56 & 64.14 & 13.55 \\
32 & 32.07 & 60.52 & 72.27 & 19.88 \\
ZHQ & 14.36 & 50.59 & 52.39 & 24.39 \\
49 & 37.94 & 45.17 & 54.20 & 28.91 \\
TXQ & 44.26 & 72.27 & 62.27 & 23.49 \\
HLMQ & 18.07 & 30.71 & 27.10 & 14.45 \\
GQ & 26.20 & 29.81 & 42.26 & 13.55 \\
$59-1$ & 16.26 & 20.78 & 22.58 & 26.20 \\
\hline
\end{tabular}


Appendix B. The mean values of POD activity

\begin{tabular}{lllll}
\hline POD activity & $2 \mathrm{~d}$ & $4 \mathrm{~d}$ & $6 \mathrm{~d}$ & $8 \mathrm{~d}$ \\
\hline HXZ & 5.05 & 10.60 & 12.10 & 8.20 \\
HL & 6.64 & 11.30 & 19.00 & 15.60 \\
HQ & 13.27 & 16.54 & 25.50 & 19.50 \\
XBL & 6.70 & 11.10 & 20.30 & 18.50 \\
Control & 13.70 & 15.60 & 16.13 & 26.70 \\
29 & 8.16 & 19.40 & 20.77 & 21.64 \\
30 & 5.61 & 12.29 & 14.05 & 12.11 \\
$31-2-1$ & 6.02 & 7.54 & 13.04 & 19.53 \\
$31-2-2$ & 4.54 & 6.67 & 17.84 & 15.16 \\
32 & 6.32 & 14.36 & 15.27 & 15.75 \\
ZHQ & 9.96 & 14.12 & 16.90 & 18.26 \\
49 & 8.03 & 13.39 & 15.22 & 22.06 \\
TXQ & 5.85 & 10.96 & 11.98 & 12.29 \\
HLMQ & 11.04 & 19.45 & 14.15 & 25.95 \\
GQ & 8.70 & 20.83 & 17.61 & 17.47 \\
$59-1$ & 4.13 & 9.41 & 16.02 & 18.53 \\
\hline
\end{tabular}

Appendix C. The mean values of SOD activity

\begin{tabular}{lllll}
\hline SOD activity & $2 \mathrm{~d}$ & $4 \mathrm{~d}$ & $6 \mathrm{~d}$ & $8 \mathrm{~d}$ \\
\hline HXZ & 719.7 & 977.1 & 916.2 & 930.9 \\
HL & 623.1 & 717.6 & 941.4 & 832.2 \\
HQ & 789.1 & 895.2 & 919.4 & 834.3 \\
XBL & 716.6 & 954.0 & 999.3 & 842.7 \\
Control & 885.8 & 953.0 & 1001.4 & 904.7 \\
29 & 684.0 & 983.9 & 1075.5 & 844.6 \\
30 & 460.0 & 861.0 & 885.0 & 731.0 \\
$31-2-1$ & 714.0 & 906.0 & 963.7 & 838.5 \\
$31-2-2$ & 834.9 & 1007.0 & 961.4 & 966.0 \\
32 & 616.7 & 754.0 & 1018.9 & 846.5 \\
ZHQ & 702.0 & 718.7 & 817.0 & 900.0 \\
49 & 717.0 & 757.7 & 908.1 & 858.0 \\
TXQ & 670.3 & 742.6 & 943.9 & 822.0 \\
HLMQ & 950.0 & 999.0 & 1026.5 & 1040.9 \\
GQ & 768.6 & 957.5 & 930.8 & 706.3 \\
$59-1$ & 726.1 & 835.0 & 992.0 & 974.8 \\
\hline
\end{tabular}


Appendix D. The mean values of MDA content

\begin{tabular}{lllll}
\hline MDA content & $2 \mathrm{~d}$ & $4 \mathrm{~d}$ & $6 \mathrm{~d}$ & $8 \mathrm{~d}$ \\
\hline HXZ & 0.0100 & 0.0114 & 0.0178 & 0.0110 \\
HL & 0.0122 & 0.0134 & 0.0180 & 0.0151 \\
HQ & 0.0080 & 0.0163 & 0.0193 & 0.0080 \\
XBL & 0.0060 & 0.0080 & 0.0176 & 0.0081 \\
Control & 0.0110 & 0.0141 & 0.0250 & 0.0206 \\
29 & 0.0070 & 0.0118 & 0.0135 & 0.0120 \\
30 & 0.0062 & 0.0103 & 0.0117 & 0.0114 \\
$31-2-1$ & 0.0059 & 0.0125 & 0.0115 & 0.0072 \\
$31-2-2$ & 0.0122 & 0.0156 & 0.0086 & 0.0081 \\
32 & 0.0092 & 0.0117 & 0.0153 & 0.0081 \\
ZHQ & 0.0033 & 0.0115 & 0.0076 & 0.0050 \\
49 & 0.0094 & 0.0114 & 0.0164 & 0.0093 \\
TXQ & 0.0111 & 0.0137 & 0.0129 & 0.0071 \\
HLMQ & 0.0103 & 0.0111 & 0.0141 & 0.0122 \\
GQ & 0.0059 & 0.0061 & 0.0152 & 0.0023 \\
$59-1$ & 0.0099 & 0.0165 & 0.0100 & 0.0054 \\
\hline
\end{tabular}

Appendix E. The mean values of EL

\begin{tabular}{lllll}
\hline EL & $2 \mathrm{~d}$ & $4 \mathrm{~d}$ & $6 \mathrm{~d}$ & $8 \mathrm{~d}$ \\
\hline HXZ & 0.113 & 0.33 & 0.263 & 0.209 \\
HL & 0.112 & 0.337 & 0.204 & 0.156 \\
HQ & 0.176 & 0.416 & 0.351 & 0.184 \\
XBL & 0.094 & 0.250 & 0.156 & 0.103 \\
Control & 0.108 & 0.386 & 0.328 & 0.166 \\
29 & 0.192 & 0.179 & 0.225 & 0.183 \\
30 & 0.156 & 0.171 & 0.371 & 0.235 \\
$31-2-1$ & 0.051 & 0.117 & 0.285 & 0.134 \\
$31-2-2$ & 0.081 & 0.224 & 0.282 & 0.199 \\
32 & 0.203 & 0.183 & 0.237 & 0.161 \\
ZHQ & 0.189 & 0.243 & 0.311 & 0.206 \\
49 & 0.158 & 0.203 & 0.206 & 0.185 \\
TXQ & 0.182 & 0.266 & 0.269 & 0.175 \\
HLMQ & 0.294 & 0.203 & 0.206 & 0.195 \\
GQ & 0.071 & 0.159 & 0.228 & 0.127 \\
$59-1$ & 0.194 & 0.201 & 0.177 & 0.166 \\
\hline
\end{tabular}

\section{Copyrights}

Copyright for this article is retained by the author(s), with first publication rights granted to the journal.

This is an open-access article distributed under the terms and conditions of the Creative Commons Attribution license (http://creativecommons.org/licenses/by/4.0/). 